\title{
LA IDEA DE CRÍTICA DEL ARTE EN EL PENSAMIENTO ESTÉTICO DE FRANCISCO GINER DE LOS RÍOS ${ }^{1}$
}

\author{
RICARDO PINILLA BURGOS \\ Universidad Pontificia Comillas
}

\section{Resumen}

En sus lecciones estéticas, aparecidas en el BILE en 1877-1878, Giner hace una defensa de la Estética como disciplina autónoma, su valor práctico, y su relación con las artes y la literatura, respondiendo desde el horizonte fundamental de su concepción krausista a cuestiones y polémicas unidas a la Estética en el contexto cultural y político de su tiempo. A partir de un rico pensamiento estético y una amplia concepción del arte como actividad esencial humana, Giner elabora en esas lecciones, entre otras cuestiones, una idea de Crítica del Arte, en íntima vinculación con la producción de una obra singular y con la interpretación de los principios generales, que permitirá una reconsideración profunda de la actividad del crítico, que Giner ejercerá de modo brillante en distintos ámbitos, y que se abre a una importante reflexión sobre la peculiaridad y relevancia vital del juicio estético.

Palabras clave: Estética; Crítica; Principios; juicio; producción artística.

\begin{abstract}
In his Aesthetics-Lectures (BILE 1877-1878), Giner makes the case for Aesthetics as an independent subject, with a practical value of its own and its particular relationship to the Arts and Literature from Krause's thought perspective. In his work, he also answers several questions and controversies associated with Asthetics in his cultural and political context. From a starting point of rich aesthetical thought and a broad concept of art, Giner also presents in these lectures, among other topics, an idea of Criticism, in close relation with the production of a singular work of art and also with
\end{abstract}

1. Este artículo se ha realizado en el marco del proyecto de investigación FFI2011-23682: «Fundamentos y desarrollo de la idea krausista de Europa: universalismo, internacionalismo, educación y cultura».

Anales, 27 (2015), pp. 81-106

DOI: 10.14198/ALEUA.2015.27.05 
the interpretation of general principles. Giner has an interesting body of work on several arts that lead him to a conception of Criticism closely connected to an important reflection about the special meaning and relevance of the aesthetic judgment in life.

Keywords: Aesthetics; Criticism; Princips; judgment; artistic production.

\section{Dos proyectos krausianos en el universo gineriano: Estética y Ciencia del Arte}

Ya ha pasado una centuria desde la muerte de Francisco Giner de los Ríos, y su figura no deja de agrandarse y, aún más, de enriquecerse y matizarse conforme se estudia su obra. Más allá de loas y elogios, o de recordar las estelas vibrantes de su magisterio, hoy día el mejor homenaje que podemos hacer a Giner es leerlo y releerlo y ponerlo a hablar con nuestra actualidad y nuestro horizonte. Es seguro que, en ese ejercicio, la letra de don Francisco no palidecerá. Antes bien, veremos cómo revive en ella el espíritu inquieto e incansable de quien buscó con ahínco la verdad y vivió de modo muy íntimo la educación como una tarea inaplazable y siempre abierta.

Entre los muchos aspectos y contribuciones importantes que ofrece su pensamiento, el tema de la estética y las artes es sin lugar a dudas uno de los pilares que consolidaron su personalidad como maestro y verdadero forjador de cultura y de horizontes educativos para muchas generaciones. De su actividad en este campo quedan traducciones (sobre todo su crucial labor de traductor y receptor de la Estética de Krause), y su magisterio e influencia en multitud de realizaciones de todo orden relacionadas con el mundo del arte, la música, la literatura, el patrimonio artístico o las artes industriales. Pero también y sobre todo para nuestra actual reflexión, como reflejo de una meditación viva, nos llegan sus agudos escritos que plantean un pensamiento original, digno desarrollo de los postulados krausistas, y abiertos a muchos problemas estéticos y culturales de su tiempo ${ }^{2}$.

No obstante, sería algo limitado tasar la aportación de Giner a la Estética ciñéndonos a su concepción de esta disciplina. Trataré de explicarme. Diferente aunque superpuesta a la idea de una «ciencia estética», en Giner hay elementos muy importantes para una amplia «ciencia del arte» como teoría general de la acción humana y la valoración de medios y fines en

2. Estos aspectos los he desarrollado en varios trabajos: cf. 2005, 2009a, 2010, 2012. Sobre la actividad musical de Giner y la Institución Libre de Enseñanza, son ya imprescindibles los estudios de Leticia Sánchez de Andrés (2009a, 2009b). 
la realización de sus obras. En la obra de Krause hay elementos muy interesantes para ver estos dos proyectos, que, lejos de ser incompatibles, se complementan e interseccionan. En Giner se puede decir que conviven ambos sin por ello necesitar confundirse, aunque sí se relacionan en puntos muy importantes, manteniendo a su vez una sólida independencia.

En la filosofía de Krause la idea de arte pronto fue relevante como un ideal de la actividad humana, y es verdad que la concreción de esa idea de modo paradigmático como arte bello no es algo ausente en su obra, pero Krause, de una manera ya un tanto anacrónica o a contracorriente en su época, conservó en sus escritos la acepción general de arte (Kunst) como algo más amplio que el dominio del arte bello. A su vez, la idea de belleza, verdadero epicentro de la Estética krausiana, entendida como una filosofía de lo bello y del arte bello, es central en su pensamiento metafísico y acerca de lo real, y una característica esencial del Ser supremo; descubriendo en lo bello la señal de semejanza de cada ser con Dios dentro de su finitud, a la vez que concentrando en sí todo el cuadro de categorías krausianas acerca de las cosas y su realidad (unidad, diversidad, armonía) en su carácter orgánico, como una unidad cuyo contenido son diversas partes compensadas y contrastadas entre sí.

De otra parte, el arte en su más amplio sentido formó para Krause un binomio fundamental junto a la ciencia como actividad fundamental de la Humanidad. El modo en el que la íntima condición de lo humano podría realizarse consiste en ir descubriendo y conociendo la verdad a través de la ciencia, realizando lo esencial en el tiempo en los diversos ámbitos de la vida, a través de las distintas artes, no solo las bellas o libres. De ahí que la idea de arte se resuelva en Krause como la esfera de la acción y del poder hacer (können), como complemento co-esencial de la acción humana junto a la capacidad de conocer (kennen) de la ciencia (Krause, 1829: 553) ${ }^{3}$.

En el célebre artículo de Giner «El Arte y las artes», aparecido en 1871, se explora a partir de este último planteamiento la necesidad de una profundización en este concepto y se llega a un resultado contundente, que nos permite hablar de una teoría de la acción humana en tanto que acción artística en su sentido amplio. Hoy quizá utilizaríamos otras palabras como técnica, o acaso acción y actividad, pero el uso de este preciso término y el trabajo gineriano no nos permite tan fácilmente hacer esta traslación. Recordamos un conocido pasaje de ese artículo en este sentido:

3. Para una exposición del amplio pensamiento estético de Krause, cf. Pinilla, 2002, 2013.

Anales, 27 (2015), pp. 81-106 
[...] obra artísticamente quien, en la ejecución de una empresa cualquiera, procede de tal modo que toda su acción, recogida en sí misma y atenta cuidadosamente a su objeto, sin distraerse de él un punto, hace converger y servir para este con perseverancia y delicado tacto cuantos medios se requieren, hasta lograr que el resultado corresponda a su idea (Giner, 1919: 2).

Resuenan en esta definición lo mejor de la idea clásica aristotélica de tecné y la acepción krausiana del arte como la actividad originaria humana que realiza lo esencial y conforme a Ser en el tiempo (Krause, 1882: 184). Este pasaje retrata muy bien un aspecto del modo de Giner de acometer cualquier empresa: esa concentración o recogimiento cuidadoso, esa entrega al objeto del quehacer. Ahora bien, a pesar de propiciar esta reflexión una posible interpretación de la relevancia del arte para Giner en un campo ya extra-estético, cabe decir que tanto el modelo de la formación del gusto y del espíritu artístico bello, como la educación de la razón y el discernimiento para formular juicios críticos válidos en torno a las obras de arte bello (lo que se venía a denominar crítica en un sentido amplio en el mundo del arte), siempre fueron para don Francisco guías muy presentes en el contexto de su ideal formativo. Tan erróneo sería por lo tanto no distinguir los dos proyectos mencionados, como divorciarlos o meramente yuxtaponerlos circunstancialmente. En esa diferencia y relación reside posiblemente uno de los elementos más genuinos de todo el universo gineriano.

Pensar lo bello y el fenómeno estético en todas las esferas de la vida, y a la vez asumir de modo responsable y reflexivo la actividad humana como un arte general del vivir, son en definitiva esos dos horizontes bien nítidos y diferentes, pero que no dejan de fecundarse en el pensamiento krausiano y por ende gineriano. Y es desde esos horizontes desde donde cabe entender la profundidad y alcance de las reflexiones de Giner en torno a la tarea del crítico de arte y, en general, de la relación de nuestro pensamiento y juicio ante la obra humana en su diversidad, pero en esa vocación tan especial a la que es llamado el artista bello en la factura de su obra y en la expresión de esa poesía interior que, como una profunda voz y guía, le lleva a emprender el camino de la creación libre en busca de la belleza.

\section{Ubicación sistemática de la crítica del arte en las lecciones estéticas del Boletín de la Institución Libre de Enseñanza}

Entre finales de 1877 y 1878 sabemos que Giner publicaba en el Boletín de la Institución Libre de Enseñanza unas lecciones tituladas «Estética con especial aplicación a las bellas artes». En el título ya llama la atención el 
énfasis en las bellas artes, que de equipararse la Estética a la Teoría del arte parecería innecesario. Giner pretende de un lado afianzar el carácter legítimo de esta disciplina, y de otro apelar a la aplicación y valor práctico de esta en las bellas artes.

Estas ocho lecciones se presentan en ese tono modesto y funcional que encontramos en otros escritos de Giner. De hecho aparecen publicadas en el apartado del BILE titulado «Resúmenes de enseñanzas», donde se publican otros resúmenes de diversos cursos impartidos por los profesores de la Institución Libre de Enseñanza. Así, comienza don Francisco indicando que «[e]sta enseñanza tiene un carácter elemental», por lo que no pretende ser una «investigación radical», sino «una exposición de los resultados que hoy de común acuerdo aceptan en esta esfera las más diversas escuelas y partidos» (Giner, 1877: 77). En efecto, Giner nos trazará un completo estado de la cuestión y aludirá a numerosos autores, pero en absoluto son estas lecciones mero eco de opiniones «de la cultura actual». Disintiendo así de la intención manifestada por el propio Giner, creemos que, dentro de su pretensión sumaria, contienen estas lecciones algunos aspectos fundamentales de un pensamiento estético y sobre el arte muy original, con un amplio marco filosófico, a la vez que, eso sí, en respuesta directa a cuestiones que la ciencia estética planteaba en su época.

Los títulos de las lecciones desvelan un interés por dejar clara la legitimidad científica de esta ciencia (lecciones $1 .^{a}, 2 .^{a}$ y especialmente $5 .^{a}$ ), así como lo que Giner llama su valor práctico $\left(3 .^{a}, 4 .^{a}\right)$ y su relación con las teorías de las artes particulares, de modo especial con la Teoría de la Literatura $\left(6 .^{a}, 7 .^{a}\right)$; pero también con la Ciencia del Arte como tal $\left(8 .^{a}\right)$, asunto con el que concluye el ciclo y denota la nitidez con la que Giner concebía los dos proyectos o ciencias distintas: la Estética y la Ciencia del Arte, lo que no excluía por supuesto que ambas se relacionasen fecundamente en la teoría del arte estético, dado que puede haber un arte que no tenga como fin la belleza. Giner valora en esto la aportación de Krause desde su distinción de arte bello, arte útil y arte bello-útil, admitiendo que es una clasificación «de tal importancia que es la dominante», frente a otras como las de artes bellas frente a artes meramente agradables o recreativas (Kant, Jungmann), o artes independientes y dependientes (Vischer). Giner no deja de ver problemas en esta división, como es el hecho de clasificar no tanto cada obra, como él propondría, sino las artes como tales. Él entiende que todo arte es susceptible de estar encaminado a la belleza y también a la utilidad. De otro lado, se pregunta si aun en las artes estéticas, aunque el fin sea la belleza pura, en tanto que artes y por lo tanto como organización 
y manejo de unos medios y unas destrezas para un fin, no hay siempre una utilidad en un sentido profundo. Con todo, lo que valora de la clasificación de Krause es que con ella, y acaso con la indagación krausiana de la idea de arte y su amplia concepción, se nos ofrece «la primera [clasificación del arte], tal vez, en que se ha intentado abrazar la esfera total artística» (Giner, 1878: 27).

La cuestión de la legitimidad de la Estética y de su valor práctico y aplicación al mundo del arte, como nos desvelan algunos trabajos sobre la introducción de la Estética en España (Orden, 2001; Roviró, 2011), sabemos que no estaba exenta en ese momento de implicaciones indirectamente políticas, pues la Estética como disciplina autónoma respecto a la Literatura y la Retórica, y como una materia dentro de los estudios de Filosofía, se convertiría en seña de identidad del pensamiento liberal y progresista. En efecto, la nueva disciplina de la Estética, nacida en Alemania a mitad del siglo XVIII, se introduciría en España inicialmente dentro de los estudios literarios como una materia auxiliar. El ubicarla autónomamente y reclamando su base filosófica, operación propiciada especialmente por Sanz del Río y los krausistas (Orden, 2001: 262 ss.), otorgaba al análisis del hecho literario y artístico en general una libertad y un amplio horizonte, a la vez que completaba el campo del pensamiento y la formación, asumiendo la dimensión estética y la actividad artística como algo primordial y sustantivo dentro de la cultura. Cuando revisamos cómo esta materia fue incluida y suprimida en los planes de estudio de Filosofía en varias ocasiones según los cambios de orientación del gobierno de turno, comprobamos que estas cuestiones no son meras disquisiciones abstractas, a la vez que no podemos dejar de constatar que la Estética como materia filosófica se convirtió en todo un síntoma o símbolo de las pugnas entre liberales y conservadores. Por eso no es irrelevante que Giner escribiera estas lecciones precisamente en esos años, después de su importante trabajo de traducción del Compendio de Estética de Krause, aparecido como libro completo en 1874, y que aún retomaría después en una segunda edición ampliada a la luz de las ediciones extensas de la Estética y las obras sobre teoría e historia de la música krausianas (Krause, 1883).

Pero ¿qué quería decir que el filósofo estudiase Estética? De un lado que la belleza y las bellas artes eran un tema digno del pensamiento más especulativo; pero también que el profesional y estudioso del arte, a la hora de establecer criterios de valoración y en definitiva de ejercer la crítica artística, debería tener y manejar un horizonte filosófico de los problemas, y también un escrúpulo crítico con su misma forma de juzgar y de 
manejar sus juicios sobre las obras, a la hora de aplicar una supuesta regla general o canon para clasificar y valorar las obras de arte. La formación del estudioso de la literatura, que incluía la Estética como un complemento a su educación histórica y estilística, debía adquirir los vuelos necesarios de un ejercicio reflexivo y responsable de primer orden. En este sentido, recordando en parte lo que había sido la discusión en torno a la crítica del arte en el romanticismo alemán, se puede decir que Giner aspiraba a presentar, ya en estas lecciones, los rudimentos para una correcta y renovada idea de la crítica del arte.

La revisión de la idea de crítica no va a ser un excurso coyuntural o un añadido a la teoría estética, sino que viene dada desde la misma concepción de la Estética como ciencia y a la vista del programa entero de su desarrollo; para ello, Giner dialoga activamente con el proyecto de Krause, que en la Estética, en su sentido amplio, vería tres grandes partes: la puramente filosófica, la histórica-empírica y, reuniendo las otras, la filosófico-histórica (Krause, 1882: 7). En sus lecciones de Estética, Krause era consciente de desarrollar, y aun de modo no completo, la parte filosófica. Aún podría haberse completado una fundamentación metafísica mayor de estas lecciones en lo que compete al concepto de belleza, sobre todo, y también en lo referente al concepto de arte y arte bello, tal como haría en sus lecciones sobre el sistema de la Filosofía (Pinilla, 2002: 322 ss.). La parte histórica o empírica requeriría un estudio desde la experiencia del desarrollo de las artes en su diversidad y estilos, y también de la misma idea de belleza. Krause entiende que la belleza es un concepto absoluto, pero no deja de asumir que el ideal de la belleza se va desvelando a lo largo de la historia, y, en este sentido, la parte histórica sería solo artística sensu stricto. Giner corroborará y apoyará este amplio planteamiento. Finalmente, la parte tercera sería una filosofía a la vista de ese desarrollo histórico y empírico. Krause es consciente de que no puede desarrollar esta parte, y hay que recurrir a algún manuscrito y sobre todo quizá a sus trabajos musicológicos amplios (su Teoría de la Música y su Historia de la Música) para entender las dimensiones de su proyecto y sus tres fases o partes (Pinilla, 2013: 121 ss.).

En la segunda lección de las mencionadas, bajo el título «El carácter de la Ciencia Estética», planteará Giner este asunto, resultando en ella al final el esquema general de esta disciplina y el carácter de cada una de las partes. Es ahí donde aparecerá el tema de la Crítica. Giner señala que la Estética hegeliana en realidad ha marcado el desarrollo de esta disciplina, aunque disiente de la idea de reducirla a una ciencia o filosofía del arte. 
Giner hace aquí una lectura sintética pero certera de Hegel, pues aunque en sus lecciones estéticas se aborde preliminarmente el concepto de belleza y de belleza natural, no es este concepto en realidad el rector de su pensamiento estético, sino el de «la idea de lo bello artístico» (Idee des Kunstschönen) (Hegel, 1986: 127 ss.), acorde con la valoración hegeliana del arte como creación del espíritu que, en este sentido, está en un nivel superior a cualquier belleza natural.

Hecha esta consideración, Giner plantea abordar «el problema de la belleza» apelando «a la observación y al sentido común culto y no a teorías preconcebidas» (Giner, 1878: 4), y desde ahí no duda en señalar que es la belleza el objeto central de la Estética, pues el «fenómeno estético» puede encontrarse en las obras de arte, por supuesto, y se diría que en ellas de modo muy especial, pero también «en la vida ordinaria». En realidad, como en otras ocasiones, Giner sigue aquí a Krause, quien comenzaba sus lecciones estéticas apelando al sentido común, para desgranar la belleza como su objeto central. La consideración de la belleza más allá del arte, en el enfoque krausiano, no es en realidad un problema de grado, como plantearía Hegel, sino que, antes de nada, hay que considerar lo bello como un rasgo esencial de lo real y de Dios, entendido este como Ser y Ser supremo. Como tal, la belleza es susceptible de manifestarse en todas las cosas, sin perjuicio del valor ejemplar del arte. Pero Giner no quiere en sus lecciones prescribir grandes fundamentos metafísicos, sino, siguiendo el objeto didáctico de estas, acompañar al pensamiento del oyente y del lector.

La asunción de la belleza como una dimensión de la realidad posee para Giner tres niveles diferentes aunque interrelacionados: $\left.1 .^{\circ}\right)$ percibir lo bello en un objeto individual, como algo específico y diferente de otras características; $2 .^{\circ}$ ) juzgar su valor y grado de belleza; $3 .^{a}$ ) y finalmente indagar las razones y fundamentos de nuestro juicio. A estos niveles Giner los llama problema individual, problema crítico, y problema general o filosófico, que pondrá en relación con las tres partes o «ciencias particulares» pertenecientes a la Estética: la «Historia de las manifestaciones estéticas»; la «Estética crítica», que sería una de las dos partes de la Estética filosóficohistórica; y la «Filosofía de lo bello». Al enumerar estas ciencias, Giner coloca la tercera (Filosofía de lo bello) en segundo lugar. Este cambio es significativo, pues atiende ya no a una exposición descriptiva ascendente, que correspondería a las acciones de observar, juzgar y buscar el fundamento; sino a un orden sistemático, en donde el juicio crítico ha de tener como base tanto la observación empírica e histórica como la fundamentación filosófica. La crítica así se inserta, sin agotarla tal vez, en la parte 
más compleja o sintética de la Estética, en donde se han de combinar los conocimientos histórico-empíricos con la fundamentación filosófica en primer lugar de la idea de belleza, como concepto central de todo el fenómeno estético.

Aunque Giner está hablando del carácter y de las partes de la disciplina de la Estética, ya podemos suponer el alto valor que asignaba al oficio de crítico de arte, incidiendo con esto en un contexto de preocupación de muchos intelectuales y literatos españoles por armar a la crítica de una fundamentación sólida, y curarla de caer en un mero ejercicio arbitrario y caprichoso. En su estudio sobre la Teoría del arte del krausismo español, Francisco J. Falero nos recuerda con detalle este contexto que se remonta a las preocupaciones del movimiento ilustrado y romántico, aludiendo a autores como Milá y Fontanals o Menéndez Pelayo y su Historia de las ideas estéticas, entre cuyas motivaciones, señala, estaría esa necesidad de fundamentar la crítica del arte desde la misma historia y conceptos de la Filosofía y la Estética (Falero, 1998: 93 ss.). En esa línea incluye también Falero a quien fuera maestro de Giner en temas estéticos: Francisco Fernández y González, y también alude a institucionistas como José Echegaray, Hermenegildo Giner y el mismo Manuel de la Revilla, del que analiza un interesante discurso pronunciado en el Ateneo madrileño en 1879. Se trata de un discurso resumen dentro de la sección de literatura, que llevaba el significativo título de «Principios a que debe obedecer la crítica literaria para influir provechosamente en la educación del gusto y en el desarrollo del arte». Al parecer, Fernández y González había impartido un curso sobre «Crítica de literatura y artes» entre 1876 y 1878 en el Ateneo, del que no se conserva su contenido. Fernández y González contribuyó sin duda a presentar en el ámbito cultural español la Estética como una ciencia filosófica de primer orden, y en íntima relación con el desarrollo último de la filosofía, especialmente en Alemania a partir de Kant, el romanticismo y el idealismo, momento que históricamente coincide también con la necesidad de una refundación de la crítica literaria y del arte en sus implicaciones filosóficas, culturales y políticas.

Las lecciones de Giner son coetáneas a los cursos y discursos del Ateneo mencionados, y por ello sus alusiones a la Crítica y su ubicación y fundamentación sistemática cobran especial relevancia y significado. Giner apela inicialmente al problema de una ubicación sistemática de la Crítica dentro del plan completo de la ciencia estética, con lo que el oficio del crítico encuentra ya de partida un horizonte científico y filosófico de indudable alcance. En realidad Giner, con las partes señaladas de la Estética, 
sigue muy directamente la división ya aludida de Krause, que organiza el plan completo de esta ciencia en una parte histórica o empírica, una parte filosófica, y una tercera que sería una «Filosofía de la Historia de lo bello y del arte» (Pinilla, 2005: 72; Krause, 1837, §4: 3). En la primera edición de la traducción del Compendio de Estética de Krause, Giner traduce literalmente la denominación de esta parte (Krause, 1874: 5), si bien en sus lecciones del BILE (1877-1878), como hemos visto, no duda en incluir la Crítica en esa tercera parte; en la segunda edición del Compendio de Estética modifica la denominación de esa parte, nombrándola como «ciencia filosófico-histórica o crítica de lo bello y el arte» (Krause, 1883: 4). No hay que ver, no obstante, esta variación como una suerte de incursión externa, o adaptación de esta parte a las ideas ginerianas. El mismo Krause observa que en esta parte se hace posible una acogida y un aprecio de lo bello y el arte en todas sus manifestaciones:

Ese conocimiento científico [la Filosofía de la Historia de lo bello y del arte] implica primeramente que el que lo posee acoge todo lo bello que encuentra en la unidad de la idea [de lo bello], y lo comprende y aprecia, y por otro lado como artista configura con riqueza artística todo lo bello individual en la intuición íntima de la idea de lo bello (Krause, 1882: 7).

Esta declaración no aparece como tal en el Abriss der Aesthetik (Compendio de Estética), sino en las lecciones amplias de Estética, concretamente en las Vorlesungen der Aesthetik, que se publicaban póstumamente de la mano de Hohlfeld y Wünsche en 1882, y que Giner tuvo presentes a la hora de revisar la traducción del Compendio de Estética. La modificación aludida, aunque leve, vemos cómo se hace eco de la profundización en la articulación de esta parte por el mismo Krause, en confluencia con el planteamiento del propio Giner ya expresado con nitidez en sus lecciones estéticas impartidas en la Institución. Si reparamos brevemente en el pasaje aludido, vemos cómo, más que de un oficio concreto del crítico, Krause habla de una relación comprensiva o contemplativa, junto a una más directamente activa. El ser humano, desde la ciencia estética, quedaría facultado para ambas, tanto para el juicio y valoración de lo bello y el arte, como para la realización concreta de lo bello, en tanto que artista. Es sin duda un horizonte amplio en el que se inscribe la tarea del crítico, y que compartiría con la misma actividad el artista; un horizonte de conocimiento histórico y de reflexión filosófica, que, si no siempre presente, se señala como deseable, a la luz del amplio proyecto tripartito de la ciencia estética krausiana, y que Giner asume con viveza. 
Es verdad que las lecciones estéticas de Krause ni siquiera en sus ediciones amplias contemplan el desarrollo completo de las tres partes, siendo sin duda un programa ambicioso, acaso solo realizado en el campo de la teoría musical. Lo que sus lecciones desarrollan es más bien la parte puramente filosófica: una amplia filosofía de la belleza, una filosofía o teoría del arte y las teorías particulares de cada arte, faltando el desarrollo de la parte empírica e histórica y la parte tercera, filosófico-histórica. Ahora bien, ya en la teoría del arte (segunda parte principal de su Estética), Krause contempla, dentro de lo que llamará el círculo del arte, la figura del juez o del conocedor de arte (en el que se incluirían no solo los críticos, sino los historiadores y estudiosos del arte en toda su amplitud) (Pinilla, 2002: 876 ss.). Ese oficio en realidad, a la vista del programa completo de la Estética, debería partir, de acuerdo con lo expuesto, de una amplia fundamentación filosófica, del conocimiento de la idea de lo bello y del arte, así como de un conocimiento empírico e histórico del desarrollo del gusto y de las artes en los diversos pueblos y épocas.

Cuando Giner apela a las partes de la Estética, es interesante reparar en que procura reconstruir un proceso, que podríamos llamar más experiencial o fenomenológico, que no corresponde todavía directamente con el esquema sistemático y conceptual. Este planteamiento nos indica que Giner no solo está interesado en una suerte de legitimación académica o sistemática de la Crítica, sino que inscribe a esta en un marco amplio de relación con el fenómeno estético, en ese marco que va de la observación dispersa al juicio, y que apela en definitiva a la búsqueda de fundamentos. El horizonte amplio o macroscópico de este planteamiento experiencial se traduce en el desarrollo de un conocimiento empírico e histórico, una reflexión filosófica amplia, y una síntesis de ambos desarrollos. De estas partes, apunta Giner que es la Historia del Arte la más desarrollada de la parte empírica, dando a entender, acorde con el planteamiento krausiano, que habría una ciencia empírica e histórica más amplia que abordaría no solo el arte, sino el fenómeno de lo bello y lo estético en general. Esto, que en su momento podría parecer un planteamiento algo abstracto y con un referente impreciso, se ha demostrado un objeto fecundo en la Estética en el siglo Xx (en autores como W. Benjamin, Auerbach o H.-R. Jauss), que aborda también una historia de los modelos de experiencia estética (no simplemente un desarrollo de diferentes cánones estéticos).

Giner tiene a la vista el gran despliegue de la Estética hegeliana, que en principio consideraría el aspecto histórico y de desarrollo del ideal de lo bello artístico a lo largo de diferentes etapas o figuras desde la antigüedad 
(forma simbólica, clásica, romántica). Es significativo observar que en este sentido la propuesta hegeliana, que no duda en admitir como la dominante, no acaba de resultarle satisfactoria, y parece que no realizaría en realidad esa tercera parte de síntesis entre lo filosófico y lo histórico, siendo más bien un repliegue de los dos elementos hacia lo puramente filosófico. En otras palabras, vería una síntesis precipitada en el, de otro lado, magno programa hegeliano:

Para Hegel, la Historia del arte (a que reduce toda la de la belleza) no expresa sino la serie de los grados que necesariamente ha tenido que recorrer el espíritu en su manifestación, por ley indeclinable de su naturaleza: de donde el problema histórico en la Estética, como en todo (según el principio de la doctrina hegeliana) se convierte en filosófico, planteándose y resolviéndose en el dominio de la idea pura (a priori). Mas, de todos modos, la evolución del arte y la crítica de sus obras entra de un manera esencial, no por vía de mera aplicación y de ejemplo, en la Estética de aquel filósofo (Giner, 1878: 4).

Giner viene a ver de un lado una cierta reducción del problema histórico de lo estético a la historia del arte, y de otro cierta conversión urgente de lo histórico bajo el prisma filosófico. La concesión posterior, frente a estéticas más racionalistas, admite que en Hegel hay una consideración del arte y la crítica en sus desarrollos concretos. En otras palabras, a pesar de la censura a Hegel no piensa que supedite su análisis de modo artificial o forzado a su ideal de lo bello.

Al decir que no opera Hegel «por vía de mera aplicación», es posible que Giner tuviera en mente algunos estéticos franceses racionalistas, como Th. S. Jouffroy o Charles Lévêque, quien en su Estética precisamente entendía el abordaje del arte como una aplicación de los principios de la «ciencia de lo bello». En 1862 publicaba Lévêque en París La science du beau, étudiée dans sus principes, dans ses applications et dans son historie. Justo en 1878 aparecía en Valladolid la traducción de esta obra, con el título de Estética o Ciencia de lo bello, a cargo Santos Santamaría del Pozo, catedrático de Principios generales de Literatura y Literatura española en la universidad vallisoletana. En el prefacio del traductor, aclaraba que había traducido las dos primeras partes: los principios sobre lo bello y las «aplicaciones», donde abordaba el arte, la poesía y la elocuencia. Quedaba clara la intención de suministrar principios sólidos a los estudiantes de literatura e insistía este estudioso de la literatura en la idea de «aplicación» de los principios. 
Giner abogaba naturalmente por una reflexión filosófica y de los principios, pero se distanciaría de una aplicación meramente descendente o deductiva de un principio o un ideal a la obra concreta o al ejemplo o caso analizable, sea en el oficio crítico, sea en la mera apreciación de algo bello. En las notas a la traducción del Compendio de Estética de Krause, encontramos una alusión crítica precisamente a los estéticos racionalistas franceses, citando expresamente a Lévêque y Jouffroy, que pretenden juzgar algo bello desde una idea previa o un ideal. El pasaje es un momento central de la indagación krausiana de lo bello, en la que el filósofo alemán afirma que algo bello es bello «por lo que es, no por lo que significa, de ahí que tampoco se le conozca comparándolo con otro término, siendo como tal incomparable, ni por tanto con lo feo y deforme, ni con esferas superiores de belleza, ni con la idea de esta, ni con el bello ideal [...], sino que debe lucir por sí propio, por ser precisamente la idea realizada, el ideal vivo» (Krause, 1883, §12).

Es al final de esta reflexión (Compendio de Estética, §12) cuando Giner introduce en nota la crítica a la Estética racionalista francesa. Krause plantea esta importante tesis en la dilucidación de la objetividad de lo bello y la idea objetiva de belleza, y defiende, en una línea cercana en esto a como lo haría Solger (Pinilla, 2002: 479 ss., 487), la entidad de algo bello frente a su significado, o el ideal bajo el que se sustenta. Si algo es bello por el ideal o la idea a la que remite, lo bello quedaría como mera mediación, y se disolvería la patencia y el valor intrínseco de eso bello, como mero signo o alusión, desplazándose el problema de la belleza a ese ideal. Esa reivindicación de la fuerza de algo en su belleza concreta la encontramos en algunas de las más señeras consideraciones de la metafísica de lo bello, así en el Fedro platónico (Platón, 1988, 250d ss.), o en Kant, cuando determinaba que el juicio estético puro, si debía prescindir de todo concepto, no podría ser un juicio basado en un ideal de belleza (Kant, 1986, §17).

Nos interesa destacar la ubicación de esa alusión, en relación con el tema de la organización sistemática de la Estética y la ubicación de la Crítica. Para Giner estos asuntos tienen una clara relación, y advierte que, tanto en las estéticas espiritualistas e idealistas como en las positivistas, se asumen de manera rígida y abstracta una serie de principios generales; aunque en el caso de las positivistas, estos principios queden sin reconocer (Giner, 1878: 4). Este punto de ubicación filosófica de la Estética posee en Giner un componente gnoseológico y epistemológico claro, como veremos, pero acaso tiene también directamente que ver con la naturaleza de lo que se juzga, esto es, la belleza; un fenómeno del que podemos y 
debemos pensar e indagar su esencia, pero del que no podemos derivar reglas o preceptos de modo lineal a la hora de evaluar una obra concreta.

El hecho de no reconocerse las tres partes aludidas, su independencia a la vez que su relación, es a ojos de Giner un error filosófico que está en la base de muchas cuestiones y aporías de la Estética de su tiempo, que confunden una y otra parte, y provocan un desorden de diversas cuestiones, lo que llevaría de modo erróneo a asumir tanto la crisis de la teoría y de las reglas y preceptos universales para el arte, como la visión del mismo arte como algo ya desplazado o subalterno en nuestro presente, frente al dominio de la ciencia, acorde con las tesis hegelianas del carácter pretérito del $\operatorname{arte}^{4}$. Giner apuesta por un desarrollo independiente y a la vez conjuntado de las tres partes, labor que entiende desborda esas lecciones sumarias y requeriría «las fuerzas de un reformador» (Giner, 1878: 4).

\section{Entre lo universal y lo particular: la idea de Crítica y la cuestión de la creación artística}

Una vez tenemos presente la visión crítica de Giner respecto a la idea de «aplicación» sin más de un principio a un análisis de una obra o un ejemplo concreto, deberemos revisar con distancia el mismo título de sus lecciones: «Estética con especial aplicación a las bellas artes». Queda claro que Giner no espera de la Estética una aplicación en el sentido censurado. Por eso, sin desatender el asunto o enfoque de estas lecciones, en la tercera nos habla de «las ideas relativas al valor práctico de la Estética», aclarando de partida en qué consiste esa dimensión práctica o, cabría decir, aplicada de la Estética, que no es sino la capacidad de la ciencia estética para proporcionar principios generales que orienten acciones concretas. Esas acciones a veces parece que se moverían en un plano puramente crítico intelectual, pero Giner piensa sin duda también en el plano práctico operativo del mismo artista. En este sentido, el problema del juicio -o la aplicación de un principio a un caso- no quedaría circunscrito al oficio habitual del crítico, sino que apelaría también al problema mismo de la creación y la producción del arte desde el seguimiento, aplicación u observación de unos principios o leyes.

4. En su prefacio a Estudios de literatura y arte, fechado el 20 de junio de 1876, Giner hacía una aguda crítica de las tesis hegelianas sobre el fin del arte, reconociendo un momento crítico, pero no por eso de final en el arte de su tiempo (Giner, 1919: XXXI ss). Sobre este asunto, cf. Pinilla, 2009a: 144 ss. 
Giner acude aquí de nuevo a la historia y nos presenta dos grupos opuestos: aquellos que niegan el valor práctico a la Estética, considerándola solo como una ciencia teórica (y más centrada en la idea de belleza), y aquellos que, por el contrario, sí defienden el valor práctico de esta disciplina (y se centran más en el arte). Hay otros, como por ejemplo Vischer, según nos indica Giner, que colocan la Estética más allá de esta división entre lo teórico y lo práctico. De otro lado, donde más se encuentra un tratamiento aplicado de los principios estéticos a la estimación concreta del arte o a la caracterización de las reglas de la creación, es en el mundo de los tratadistas, llamados de modo general «preceptistas», que han escrito obras con esa intención explícita de determinar principios y criterios orientativos a la acción y a la contemplación. Así, piensa Giner en el elenco clásico de Poéticas, desde Aristóteles, Horacio o Vitrubio, y los tratadistas y artistas del Renacimiento, hasta los poetas, artistas, historiadores, tratadistas y críticos del Neoclasicismo, como Boileau, Raphael Mengs, Hugo Blair, Winckelmann o Moratín. El objeto y método principal sobre todo de los tratados neoclásicos era establecer unos cánones a partir de obras ejemplares que servirían como modelos para imitar. Giner cree que este planteamiento pretende convertir en absoluto y modelo fijo e inmóvil algo que en realidad es concreto y temporal, y que en general en este planteamiento de los llamados preceptistas (entendemos que sobre todo en los neoclásicos) hay una falta de análisis filosófico previo de la idea de belleza y de arte como tal; lo que lleva a no distinguir en las obras maestras lo que tienen de universal y lo que pertenece a su tiempo y a las circunstancias históricas. De otro lado, no deja de ver Giner una tendencia a dogmatizar en exceso los criterios sobre el hacer artístico de uno u otro tipo heredado de tratados clásicos, como pueden ser las unidades aristotélicas de la tragedia, o el canon dórico de Vitrubio.

Giner no niega el valor de muchas aportaciones de los llamados preceptistas, sino que rechaza sobre todo su método y su afán de establecer la crítica de arte como una suerte de código o conjunto de cánones y recetas que, más que criterios universales, retratan una concepción histórica y concreta del arte y de la producción artística, la neoclásica, que no hay que considerar como la única posible y ni mucho menos la más perfecta, como de algún modo sí pretendían prescribir teóricamente este tipo de tratados.

Frente a este universalismo rígido y excluyente de los preceptistas, ubica Giner la reacción romántica, que negaría la existencia de toda regla para el arte, y sometería la creación a la «dictadura del genio». Hay que señalar que, en sus artículos literarios, Giner distingue entre un 
romanticismo excesivo y uno más «sensato», en relación con el sentimiento y la arbitrariedad del genio, apreciando en este movimiento en todo caso la conexión con la vida y la raíz genuina de lo popular, algo que quedó extinto en el clasicismo francés más radical. En el campo concreto de la crítica, no parece Giner valorar explícitamente la preocupación de autores como F. Schlegel por renovar precisamente la actividad del crítico desde la nueva filosofía alemana. Se puede decir de otro lado que en Giner hay un progresivo distanciamiento y matización del romanticismo, al menos en la utilización de este término, que contrastaría con una inicial adhesión a este movimiento en su factura más original (romanticismo alemán e inglés) ${ }^{5}$.

En este sentido encontramos un pasaje muy interesante para nuestro tema en su artículo "Consideraciones sobre el desarrollo de la literatura moderna». Giner está sintetizando ahí dos ingredientes fundamentales en el arte de toda época, a saber: la combinación y presencia de aspectos universales, referentes a las «leyes necesarias de lo bello»; y la relación con lo temporal y con el contexto de la civilización en el que cada obra nace. En otras palabras, el buen arte debe combinar «lo accidental y lo absoluto». Si falta alguno de estos aspectos, las obras quedarán condenadas a ser producciones caducas y efímeras. A continuación, en la versión primera de este pasaje, Giner señala que «[t]ales son los fundamentos de la esthética del romanticismo» (1862: 423). En la versión revisada de este texto, pocos años después, preparada para su libro Estudios literarios, ya aparece sustituida la expresión «esthética del romanticismo» por la de «crítica moderna» (1866: 15). Esta sustitución se podría interpretar, de un lado, como un distanciamiento, pero de otro, como una comprensión del romanticismo en su impulso original en cuanto momento fundador de una nueva idea ya no de arte, sino de crítica de arte como tal, que asumiera tanto el elemento universal y metafísico del arte, cristalizado en la idea de belleza, como el aspecto temporal, histórico y circunstancial.

Si volvemos a la alusión a «los críticos románticos» en las lecciones del BILE, vemos que esa consideración de la «Crítica moderna», sea identificada con el mismo romanticismo o con su sustitución, no aparece, y pervive más la idea negativa y polarizada de una reacción romántica frente

5. Véanse los cambios y matizaciones en las alusiones al romanticismo a la luz de la comparación de la primera edición (1862) y la posterior revisión (ya de 1866 y aún reeditada por Giner en 1876) del importante artículo «(Algunas) consideraciones sobre el desarrollo de la literatura moderna». Sobre este asunto, cf. Pinilla, 2009a: 143 ss. También, Giner, 1919: 231, 233. 
a los excesos del preceptismo neoclásico y su imposición abstracta de cánones. Giner personaliza esta posición en Victor Hugo, pensando seguramente en su célebre «Prefacio» de Cromwell (1827), donde se defiende de las censuras neoclásicas y apela a la creación libre de la subjetividad del artista frente a cánones establecidos. Giner piensa que ese modo de reacción romántica y defensa de la libertad subjetiva provoca una negación de la capacidad práctica de los principios en la crítica heredera del romanticismo, como se había dado en otros autores anteriores que basan la belleza en criterios subjetivos, como Diderot, Hume o Taine, o, de otro lado, se daría en propuestas estéticas que apelan a la creación como un proceso misterioso o inconsciente: es el caso de las Estéticas de Eduard von Hartmann, o de los estudios sobre la percepción de Helmholtz, denotando Giner con esta referencia un agudo conocimiento de las implicaciones de las investigaciones de este físico, que influiría en autores como Freud (Cros, 2011). El liberalismo de Spencer será también a juicio de Giner un elemento que contribuye a este desprestigio o abandono de la pretensión normativa práctica de los principios estéticos.

Curiosamente ambos extremos, tanto los preceptistas como los románticos y partidarios de un carácter arbitrario o no consciente y racional de la creación artística, tendrían en común la ausencia de una indagación filosófica rigurosa del fenómeno estético en sus leyes y de un análisis cuidadoso del modo de interpretar o considerar esas leyes en los fenómenos o casos concretos a la hora de juzgar una obra de arte.

Por eso la solución que plantea Giner en la siguiente lección $\left(4 .^{\mathrm{a}}\right)$ acerca del valor práctico de la Estética y sus principios contiene una exposición que ya no es histórica, sino mucho más sistemática y argumentativa. Ahí es donde encontramos condensada su propuesta o consideración filosófica acerca del modo adecuado de aplicar los principios al caso concreto, y esto tanto para una consideración o juicio sobre la obra concreta, tarea propia del crítico, como para la acción misma del artista a la hora de producir su obra, de acuerdo con unas reglas o leyes generales. A pesar de las alusiones a la parte crítica, Giner parece así resolver el tratamiento de esta parte en la que se pone en relación lo general con lo particular, como campo práctico de aplicación de los principios, tanto en el ejercicio del juicio como en la misma acción artística.

Giner comienza describiendo un panorama errático a la hora de entender el sentido de los principios generales de la Estética y su aplicación en los casos particulares, como si «el artista tuviese una guía exterior para cada uno de los diversos pormenores a que debe atender» (1878: 19). 
Como se ve, Giner piensa primeramente en el artista más que en el crítico, si bien abordará desde este dilema el problema de la elaboración del juicio concreto a partir de un principio estético general.

La explicación de ese estado de error es que hay una oposición radical entre el principio general y el caso individual. La regla no puede «aplicarse de manera inmediata y directa», pues «se necesita enlazar ambos extremos, lo universal y lo particular merced a un proceso intermedio de interpretación y asimilación» (Giner, 1878: 29). Se podría aquí decir que Giner apela a una teoría comúnmente aceptada de juicio, y que Kant perfiló con agudeza en su idea de «capacidad de juzgar» (Urteilskraft) como facultad mediadora que hace posible, con el concurso de la imaginación y el esquematismo trascendental, subsumir lo particular en lo universal, esto es, poner en relación el fenómeno concreto con los conceptos del entendimiento. Esta idea aparece ya en el contexto de la crítica kantiana del conocimiento, en la Crítica de la Razón pura, y queda enriquecida al ahondar en ese especial tipo de juicio que son los juicios estéticos en la Crítica del Juicio (Kant, 1986a: 183 ss; 1986b, Introd. IV). En efecto, en su tercera Crítica acuña ese interesante concepto de «juicio reflexionante», por el que en juicios como los estéticos, y también en los teleológicos, se daría una subsunción sin que lo universal esté dado.

Giner no apela a esta precisa conceptología kantiana, pero lo que nos dice queda sin duda iluminado desde ella, pues apunta que, en el caso de la misma producción de la obra, se da la conjunción de lo universal en un complejo proceso que entraría en cada detalle de la misma obra:

Pero cada pormenor, cada momento de ejecución del caso concreto forma por sí un nuevo caso, con exigencias análogas correspondientes, el problema se repite hasta el último acto en que la obra termina: hasta el último golpe de cincel, por ejemplo, del escultor en su estatua (Giner, 1878: 29).

No duda don Francisco en calificar esto como un «proceso complicadísimo de continua y mutua referencia» entre el principio general y la obra. Por eso no basta conocer las leyes generales, sino que se precisan numerosas dotes de talento, tacto, dominio de la materia, etc., que quedan resumidas en su más alta expresión en la idea de «genio». Giner sigue razonando aquí de modo muy parecido a la idea de lo reflexionante en Kant, o al trabajo de la imaginación en la idea estética, que produce una representación que no se puede precisar desde un lenguaje o concepto determinado (Kant, 1986b, §49). Giner no alude como hemos dicho a la Crítica del Juicio, aunque sí deja indicado un inicial diálogo con los 
teóricos del inconsciente en la creación artística (E. von Hartmann, Dreher, Helmholzt), algo ya implícito en la idea kantiana de genio (ibid., §46).

Podemos preguntarnos, a la vista de lo planteado, si se está pensando aquí más en el puro problema de la creación artística o en el ejercicio de relación y aplicación de un principio general estético a una obra determinada. Aunque parece que, por los ejemplos dados, Giner piensa en el primer caso, esto es, en la creación del genio artístico como tal, la continuación de sus argumentos nos lleva más bien no solo a incluir la segunda opción, sino también a ampliar esta cuestión a un problema general de la interpretación de los principios en relación con la circunstancia, caso o acción concretos. Giner señala en este sentido que este problema de la relación entre lo universal y lo particular no es «peculiar de la producción estética, sino de toda obra de la vida en sus varias esferas» (Giner, 1878: 30). Estamos aquí ante la implicación del arte y del modelo de acción y comportamiento que afecta a la vida humana en toda su amplitud. Pero ¿y la crítica? ¿Dónde queda esa parte de la Estética que sintetiza precisamente lo empírico e histórico con los fundamentos filosóficos? ¿No sería esa parte el fundamento estético-filosófico de la actividad concreta del crítico de arte? Parece que así podría ser, en combinación con la reflexión filosófico-histórica, pero, a la vista de esa ampliación, esa síntesis entre lo filosófico y lo concreto (empírico e histórico) no sería solo un problema específico de la dimensión estética.

De otro lado, a juzgar por el interés que manifiesta Giner al principio de sus lecciones y en otros lugares por la fundamentación renovada de la crítica, uno echaría en falta una explicitación más clara del oficio del crítico o al menos del tema en sí del juicio estético sobre una obra concreta a la luz de los principios. En otros textos, en efecto, Giner apunta algunas condiciones de ese tipo de juicios, no como ejercicio periodístico o actividad profesional, sino en su sentido educativo más amplio. Así en un apunte sobre una excursión, titulado «La crítica espontánea de los niños en bellas artes», fechado en 1885, don Francisco señala con nitidez los dos momentos indispensables del enjuiciamiento de una obra. En primer lugar, «la definición de la obra, definición que comienza por la vaga e instintiva percepción de sus notas, hasta que la reflexión va fijándolas una a una y concluya para resumirlas en una característica sintética»; y en segundo, el «juicio respecto al mérito comparativo» de la obra en relación con otras (Giner, 1925: 57). Esto es, toda crítica tendría un momento de definición y otro de valoración y comparación. Como nos ilustra bien el citado apunte, la crítica ha de surgir en todo caso de la observación y la 
valoración directa y personal de la obra, aunque luego sea asistida desde el razonamiento y los conocimientos teóricos y filosóficos.

Pero si volvemos a las citadas lecciones, comprobamos que Giner hace una interesante y original alusión que redefine su argumentación, haciéndola aplicable al crítico y a quien se enfrenta a una obra ya acabada desde la mera actividad observante, judicativa y valorativa. Esa alusión es del mundo del Derecho, ámbito de especialización universitaria de Giner. Concretamente se refiere a la Escuela Histórica de Savigny, por «abrir el camino de la recta idea de la interpretación jurídica, como el proceso de asimilación y adaptación individual de la regla legal al caso práctico, de lo cual da un ejemplo la sentencia del juez» (Giner, 1878: 30). En efecto, en sus escritos jurídicos y sobre el concepto de la ley, Giner critica un racionalismo mecánico que aplique sin más y con rigidez inamovible la ley, por perfecta que pueda ser, al caso concreto, y se imparta desde ahí justicia. La justicia debe proceder a esa interpretación y relación de lo universal y lo concreto en sus circunstancias singulares de espacio y tiempo. Esto no es caer en un arbitrarismo o en un causalismo inconsistente. En un momento histórico, reflexiona Giner, el imperio ilustrado de la ley fue necesario para cribar el gobierno humano establecido desde el privilegio y la arbitrariedad, en definitiva desde la opresión y la injusticia, pero una vez conseguido un nivel de legalidad y de moralidad en la relación libre entre las personas, la aplicación ciega y rígida de la ley es, como vemos, un acto en contra del mismo hecho de juzgar y de valorar lo concreto a la luz de los principios ${ }^{6}$.

Otro campo interesante que Giner señala como ejemplo es el del dogma religioso y su relación con la «infinita variedad con la que se lo asimila, lo comprende y expresa el pensamiento de cada hombre, conforme su individualidad y su cultura» (Giner, 1878: 30) ${ }^{7}$.

6. Además de las lecciones de Filosofía del Derecho y otros numerosos escritos jurídicos ginerianos, son de especial interés para este asunto dos artículos de Giner de 1908 en torno al concepto de ley: «Sobre el concepto de la ley en el derecho positivo» y «Acerca de la función de la ley»; ambos reeditados con ocasión del quincuagésimo aniversario de su muerte: Giner, 1965: 17-38. Cf. también Pinilla, 2009b: 33 ss.

7. Desde aquí se podría seguir muy bien una de las claves del interesante planteamiento krausoinstitucionista sobre la religión y la educación, abiertas a la pluralidad y variedad religiosa, y alejadas tanto del dogmatismo religioso como de un laicismo cerril o una visión disolvente o relativista de lo religioso. Sobre el tema de la religión en el krausismo, cf. E. M. Ureña, 1996. A este respecto recordamos la traducción que hizo Giner del texto de Leonhardi «Religión y ciencia» (incluido en Giner, 1922), que tanto influyó en todos los profesores institucionistas. 
Sin duda, la educación del gusto y del juicio estético sería para Giner una magnífica escuela, si no imprescindible, para el ejercicio de esa interpretación y esa relación entre lo universal y lo particular, ese complicado proceso intermedio para el que no dudaba en requerir facultades geniales. Dicho ejercicio se alejaba tanto del arbitrarismo subjetivista, del juicio meramente caprichoso, como de un presunto racionalismo a ultranza. La opción gineriana no se autocomprende como un racionalismo débil o abierto a la circunstancia:

Nada más racional, según lo dicho, que protestar y condenar los cánones de los preceptistas, que quieren convertir los principios en recetas, esto es, en fórmulas abstractas, monótonas, incapaces de prestarse a aquella adaptación, y para las cuales nada representa el elemento individual (ibid.).

El enfoque gineriano permite leer las afirmaciones de los grandes teóricos y filósofos del arte como indicaciones y sugerencias, nunca como dogmas rígidos, y con ello libera al discurso filosófico de un mal trazado de la relación con la práctica que siempre resultaría tirante, y que, aun en nuestra actualidad, por un celo mal entendido en el ejercicio del pensamiento o de la acción creativa, presenta conflictos y ángulos oscuros que, a la vista del meridiano planteamiento gineriano, deberían estar más que resueltos, propiciando antes que nada una colaboración fecunda entre acción creadora y pensamiento; un pensamiento que, cuando se ejerce como crítica concreta, no deja de tener un tanto de verdadero arte.

\section{La actividad de Giner como crítico. Una meditación vital del presente artístico y la cultura}

A lo largo de su amplia y variada producción, y también en el marco de su actividad pedagógica y docente en la Institución Libre de Enseñanza, Giner nos brinda ejemplos vivos y muy válidos de su ideal de crítica, que como vemos apela a un horizonte fundamental de la relación humana entre lo universal y lo particular. Basta recordar sus artículos sobre la nueva pintura en Inglaterra (los prerrafaelistas) y sobre el impresionismo francés, sus numerosas críticas literarias, sus artículos sobre música y escultura, su interés por las artes decorativas y por el nuevo movimiento de Arts \& Crafts, o sus estudios sobre artes industriales ${ }^{8}$. A estos trabajos habría que

8. Hace unos años, Adolfo Sotelo publicaba una espléndida antología de Giner, titulada El Arte y las Letras y otros ensayos, donde precisamente potenciaba esta faceta amplia de 
añadir sus numerosos artículos sobre la arquitectura y el patrimonio artístico tanto de España como de Portugal, reunidos en ese maravilloso libro titulado Arqueología artística de la Península, en el que Riaño compilaba y ordenaba buena parte de estos trabajos (Giner, 1936). En todos estos escritos muestra Giner un conocimiento de detalle que se manifiesta en la observación y la información sobre las obras y los diversos movimientos o planteamientos estéticos. No ahorra Giner la crítica, pero siempre orientada desde sólidos fundamentos provenientes de su pensamiento estético. Esos fundamentos no le impiden, sobre el trabajo mismo de análisis, elaborar conceptos, comparaciones o aserciones concretas; como, por ejemplo, esa interesante comparación de las categorías de lo romántico y lo simbólico en la nueva música y la cuestión de la ausencia del realismo o naturalismo en el desarrollo de la música (Giner, 1894: 118 ss.), o la valoración de la profundización de las nuevas técnicas del arte moderno, aún deficiente a su juicio, en la pintura contemporánea en comparación con la clásica, así como sus interesantes reflexiones sobre el dilema en la creación de su tiempo, entre lo decorativo y lo útil, de un lado, y de otro la creación autónoma de la obra (Giner, 1900: 89 ss.). No solo hay que ver en estos trabajos la curiosidad inagotable de un intelectual vivo y atento a cuanto le rodeaba, o las expresiones de un amante de toda manifestación artística, que también, sino el ejercicio pulcro y responsable del tránsito y la conjugación de la observación, el pensamiento de los fundamentos y la valoración concreta de cada obra y cada problema planteado.

De los numerosos trabajos aquí solo aludidos, cabría elegir algunos de los artículos de Arqueología artística de la Península, o quizá el que versa sobre el impresionismo, como modelos de ejercicio crítico. Por otro lado, el titulado «¿Qué son las artes decorativas?», aparecido en el BILE en 1900, es todo un ensayo sobre la situación del arte contemporáneo, especialmente atendiendo a las tendencias de ese momento pujantes en Inglaterra en el campo de las artes plásticas y la arquitectura, y donde reflexiona con lucidez sobre los nuevos desafíos tanto técnicos como sociales y filosóficos.

En todos los escritos mencionados advertimos que el crítico siempre da paso al gran pensador, atento a la vida en su manifestación plural; por eso contienen estos textos meditaciones de gran calado también sobre el problema del arte y de la expresión humana como tal, y su relación con

Giner como crítico y reunía, junto a otros escritos, buena parte de los artículos y textos de esta naturaleza: cf. Giner, 2007; cf. también Giner, 1886, 1894, 1895, 1900, 1916, 1919: 237 ss., 1923, 1926, 1936. 
la cultura y la historia, sin por ello desviar en ningún momento el rigor analítico de estilos, obras y autores. En su bello texto sobre «Cómo empezamos a filosofar», aparecido en el BILE en 1887 (Giner, 1925: 15 ss.), don Francisco no dudaba en poner la educación del gusto como un ejercicio afín y paralelo a la formación del mismo pensamiento, y en ambos casos, cifraba la madurez en esa formación cuando de la obra del filósofo, o de la obra de arte, se pasaba a admirar la vida y sus manifestaciones cotidianas y concretas como obras aún superiores o más sugerentes. En este sentido, cabe presumir que el ejercicio del crítico, insertado en el saber que propicia un pensamiento estético amplio, tanto en su conocimiento histórico del arte como en sus fundamentos filosóficos, se yergue para Giner como una actividad fundamental del saber humano abierto a enriquecer la vida en toda su extensión, tanto en nuestra relación con el entorno, como con los demás y con la historia.

\section{Bibliografía citada}

\section{De Francisco Giner de los Ríos}

\section{1.a. Artículos}

«Algunas consideraciones sobre la literatura moderna», Revista Meridional [Granada], I (1862), pp. 65-72; 109-116; 137-147; 212-218; 329-333; 413-425. «Estética con especial aplicación a las bellas artes», BILE [Boletín de la Institución Libre de Enseñanza], 20 (1877), pp. 77-78.

«Estética con especial aplicación a las bellas artes», BILE, 22 (1878), pp. 4-5; 24 , pp. 21-22; 25, pp. 29-30; 27 , pp. 45 ss.; 29, p. 61; 33, pp. 92-93; 35, pp. 106-107.

«La pintura contemporánea en Inglaterra. Los Pre-Rafaelistas», BILE, 222 (1886), pp. 129-132.

«La música romántica y la música simbolista», BILE, 404 (1894), pp. 117-119. «La pintura impresionista francesa», BILE, 420 (1895), pp. 83-90.

«¿Qué son las artes decorativas?», BILE, 480 (1900), pp. 88-91.

«Cartas literarias», BILE, 671 (1916), pp. 48-54.

«¿Por qué la escultura griega es superior a las demás?», BILE, 755 (1923), pp. 58-61.

\section{1.b. Libros}

Estudios literarios, Madrid, R. Labajos, 1866.

Estudios de literatura y arte. Obras completas, III, Madrid, La Lectura, 1919. 
Estudios filosóficos y religiosos. Obras completas, VI, Madrid, La Lectura, 1922.

Educación y enseñanza. Obras completas, XII, Madrid, La Lectura, 1925.

Estudios sobre artes industriales y cartas literarias. Obras completas, XV, Madrid, La Lectura, 1926.

Arqueología artística de la Península. Obras completas, XX, Madrid, Espasa-Calpe, 1936.

Ensayos y cartas. Edición homenaje en el cincuentenario de su muerte, México D. F., Tezontle / FCE, 1965.

El Arte y las Letras y otros ensayos, ed. Adolfo Sotelo Vázquez, Sevilla, Fundación José Manuel Lara, 2007.

\section{Otra bibliografía citada}

Cros, E., «El campo cultural de la segunda mitad del XIX y su articulación con la historia (Freud, Saussure, Poética, Pintura abstracta)», Sociocriticism, 26, 1-2 (2011), pp. 69-109.

FALERO, Francisco J., La Teoría del arte del krausismo español, Granada, Universidad de Granada, 1998.

HEGEL, G. W. F., Vorlesungen über die Ästhetik, I, Frankfurt a. M., Suhrkamp, 1986.

KANT, Kritik der reinen Vernunft. Werke in zehn Bänden, III-IV, ed. W. Weischedel, Darmstadt, Wissenschaftliche Buchgesellschaft, 1986a.

- Kritik der Urteilskraft und Schriften zur Naturphilosophie. Werke in zehn Bänden, VIII, ed. W. Weischedel, Darmstadt, Wissenschaftliche Buchgesellschaft, 1986b.

KRAUSE, K. Ch. F., Vorlesungen über die Grundwahrheiten der Wissenschaft, zugelich in ihrer Beziehung zu dem Leben. Nebst einer kurzer Darstellung und Würdigung der bisherigen Systeme der Philosophie, vornehmlich der neuesten von Kant, Fichte, Schelling und Hegel, und der Lehre Jacobi's. Für Gebildeten aus allen Ständen, Gotinga, 1829.

- Abriss der Aesthetik oder der Philosophie des Schönen und der schönen Kunst, Aus dessen Nachlass herausgegeben von J. Leutbecher, Dr. und Privatdozent der Philosophie und der Friedrich-Alexanders-Universität, Gotinga, 1837.

- Compendio de Estética, traducido del alemán por Francisco Giner, profesor de la Universidad de Madrid, Sevilla, Imprenta Girondés y Orduña, 1874.

- Vorlesungen über Aesthetik oder über die Philosophie des Schönen und der schönen Kunst, Aus dem handschriftlichen Nachlasse des Verfassers herausgegeben von Dr. Paul Hohlfeld und Dr. Aug. Wünsche (Angehängt: Drei Dresdner Vorlesungen, ein Brieffragment und eine Abhandlung über Schönheit), Leipzig, 1882.

- Compendio de Estética, traducido del alemán y anotado por Francisco Giner, profesor en la Institución Libre de Enseñanza y en la Universidad de Madrid, 
2. a edición aumentada, con la Teoría de la Música, del mismo autor, Madrid, Librería de V. Suárez, 1883.

LÉVÊQUE, Charles, La science du beau, étudiée dans sus principes, dans ses applications et dans son historie, 2 vols., Paris, Auguste Durand, 1861-1862.

- Estética o Ciencia de lo bello, traducida al español por D. Santos Santamaría del Pozo, catedrático numerario de Principios generales de Literatura y Literatura española en la Universidad de Valladolid, Valladolid, Imp. y Librería Nacional y Extranjera de Hijos de Rodríguez, 1874.

ORDEN, R. V., «La introducción de la Estética como disciplina universitaria: la protesta de Sanz del Río contra la Ley de Instrucción Pública», Revista de Filosofía, 26 (2001), pp. 241-271.

Pinilla, R., El pensamiento estético de Krause, Madrid, Universidad Pontificia Comillas, 2002.

- «Francisco Giner de los Ríos como traductor y receptor de la Estética de Krause», en P. F. Álvarez Lázaro \& J. M. Vázquez-Romero (coords.), Krause, Giner y la Institución Libre de Enseñanza: nuevos estudios, Madrid, Universidad Pontificia Comillas, 2005, pp. 53-106.

— «Arte y sociedad en Francisco Giner de los Ríos», en J. M. Vázquez-Romero (coord.), Francisco Giner de los Ríos: actualidad de un pensador krausista, Madrid, Marcial Pons, 2009a, pp. 137-198.

- «Autonomía moral e independencia judicial. Consideraciones a partir de Kant», en Miguel Grande (ed.), Independencia judicial: problemática ética, Madrid, Dykinson, 2009b, pp. 19-37.

- «La Arqueología artística de la Península de Francisco Giner de los Ríos y la contribución krausoinstitucionista a una historiografía artística del arte», en J. L. Mora et al., La Filosofía y las lenguas de la península ibérica, Madrid, Fundación I. Larramendi / Asociación Hispanismo Filosófico / Real Sociedad Menéndez Pelayo / Societat Catalana de Filosofía, 2010, pp. 209-228.

- «El pensamiento estético krausoinstitucionista», en José García Velasco \& Antonio Morales Moya (eds.), La Institución Libre de Enseñanza y Francisco Giner de los Ríos. Nuevas perspectivas, 2: La Institución Libre de Enseñanza y la cultura española, Madrid, Fundación Francisco Giner de los Ríos / Institución Libre de Enseñanza / Acción Cultural Española, 2012, pp. 278-302.

- Krause y las artes, Madrid, Universidad Pontificia Comillas, 2013.

Platón, Diálogos III: Fedón, Banquete, Fedro, ed. y trad. C. García Gual, M. Martínez \& E. Lledó, Madrid, Gredos, 1988.

Roviró, I., «La introducción de la Estética en España», Pensamiento. Revista de Investigación e Información Filosófica, 67, 251 (2011), pp. 149-159.

SÁNCHEZ DE ANDRÉS, L., «El pensamiento y la actividad musical de Francisco Giner de los Ríos. Iniciativas krausoinstitucionistas en el ámbito de la educación musical (1869-1815)», en J. M. Vázquez-Romero (coord.), Francisco 
Giner de los Ríos: actualidad de un pensador krausista, Madrid, Marcial Pons, 2009a, pp. 199-258.

- Música para un ideal. Pensamiento y actividad musical del krausismo e institucionismo españoles (1854-1936), Madrid, Sociedad Española de Musicología, 2009b.

UREÑA, E. M., «La crisis religiosa en la Alemania de mediados del siglo XIX y la alianza krausista para la religión», en P. Álvarez Lázaro (ed.), Librepensamiento y secularización en la Europa contemporánea, Madrid, Universidad Pontificia Comillas, 1996, pp. 93-128.

Fecha de recepción: 29-11-2015

Fecha de aceptación: 12-12-2015 